\title{
Enriched Music-supported Therapy for chronic stroke patients: a study protocol of a randomised controlled trial
}

Jennifer Grau-Sánchez ${ }^{1,2,3^{*}}$ (D), Emma Segura ${ }^{1,3}$, David Sanchez-Pinsach ${ }^{4}$, Preeti Raghavan ${ }^{5}$, Thomas F. Münte ${ }^{6}$, Anna Marie Palumbo ${ }^{7,8}$, Alan Turry ${ }^{7}$, Esther Duarte ${ }^{9}$, Teppo Särkämö ${ }^{10}$, Jesus Cerquides ${ }^{4}$, Josep Lluis Arcos ${ }^{4}$ and Antoni Rodríguez-Fornells $s^{1,3,11,12}$

\begin{abstract}
Background: Residual motor deficits of the upper limb in patients with chronic stroke are common and have a negative impact on autonomy, participation and quality of life. Music-Supported Therapy (MST) is an effective intervention to enhance motor and cognitive function, emotional well-being and quality of life in chronic stroke patients. We have adapted the original MST training protocol to a home-based intervention, which incorporates increased training intensity and variability, group sessions, and optimisation of learning to promote autonomy and motivation.

Methods: A randomised controlled trial will be conducted to test the effectiveness of this enriched MST (eMST) protocol in improving motor functions, cognition, emotional well-being and quality of life of chronic stroke patients when compared to a program of home-based exercises utilizing the Graded Repetitive Arm Supplementary Program (GRASP). Sixty stroke patients will be recruited and randomly allocated to an eMST group $(n=30)$ or a control GRASP intervention group $(n=30)$. Patients will be evaluated before and after a 10-week intervention, as well as at 3-month follow-up. The primary outcome of the study is the functionality of the paretic upper limb measured with the Action Research Arm Test. Secondary outcomes include other motor and cognitive functions, emotional well-being and quality of life measures as well as self-regulation and self-efficacy outcomes.
\end{abstract}

Discussion: We hypothesize that patients treated with eMST will show larger improvements in their motor and cognitive functions, emotional well-being and quality of life than patients treated with a home-based GRASP intervention.

Trial registration: The trial has been registered at ClinicalTrials.gov and identified as NCT04507542 on 8 August 2020.

Keywords: Stroke, Rehabilitation, Music therapy, Music-supported therapy

\footnotetext{
* Correspondence: jennifergrau@euit.fdsll.cat

${ }^{1}$ Cognition and Brain Plasticity Unit, Bellvitge Biomedical Research Institute, L'Hospitalet de Llobregat, 08907 Barcelona, Spain

${ }^{2}$ Escola Universitària d'Infermeria i Teràpia Ocupacional de Terrassa, Autonomous University of Barcelona, C/ de la Riba, 90, 08221 Terrassa, Spain Full list of author information is available at the end of the article
}

(C) The Author(s). 2021 Open Access This article is licensed under a Creative Commons Attribution 4.0 International License, which permits use, sharing, adaptation, distribution and reproduction in any medium or format, as long as you give appropriate credit to the original author(s) and the source, provide a link to the Creative Commons licence, and indicate if changes were made. The images or other third party material in this article are included in the article's Creative Commons. licence, unless indicated otherwise in a credit line to the material. If material is not included in the article's Creative Commons licence and your intended use is not permitted by statutory regulation or exceeds the permitted use, you will need to obtain permission directly from the copyright holder. To view a copy of this licence, visit http://creativecommons.org/licenses/by/4.0/ The Creative Commons Public Domain Dedication waiver (http://creativecommons.org/publicdomain/zero/1.0/) applies to the data made available in this article, unless otherwise stated in a credit line to the data. 


\section{Background}

Stroke is one of the leading causes of long-term disability worldwide [30]. The reduction of mortality rates, especially in developed countries, has resulted in more survivors living with disability and needing rehabilitation and long-term care and support [24, 42]. Many stroke patients experience unilateral paresis of the upper extremity, which affects the individual's autonomy in basic and instrumental activities of daily living, having a significant impact on participation and quality of life $[17,39,55,89]$.

Rehabilitation programs for stroke patients are usually delivered immediately following the stroke, when the potential for recovery is thought to be the greatest $[40,86]$. Rehabilitation aims to enable the individual to achieve the highest possible level of functioning in order to reintegrate the patient into community life [2, 83]. However, once acute rehabilitation ends, the individual affected by stroke faces multiple challenges during the chronic stage. More than one third of individuals live with some residual functional limitations in basic activities, $50 \%$ of chronic stroke patients need support with instrumental activities of daily living and 65\% suffer restrictions in their reintegration into community life $[35,55]$. These residual functional limitations correlate negatively with emotional well-being and life satisfaction, in particular with regard to vocational and leisure activities [37, 38, 91]. Despite the recommendations for maintaining an active lifestyle, stroke survivors show low levels of activity and they may even experience functional deterioration during the chronic phase [6, 12, 31, 58, 92]. However, recovery has been shown to continue well into the chronic stage and depends on dose and intensity of the interventions provided [20]. Several studies have demonstrated that home and community-based interventions can increase functional independence, participation and emotional well-being in chronic stroke patients [13, 29, 34, 78]. In this vein, there is increasing interest in developing and validating interventions for chronic stroke patients aimed at enhancing physical and psychological well-being [12].

One class of music-based intervention for stroke motor rehabilitation involve playing musical instruments with the affected upper extremity following the principles of motor learning and multimodal stimulation [33]. These interventions are feasible to apply in the chronic phase $[3,80]$. Among them, Music-Supported Therapy (MST) aims to enhance the motor function of the paretic upper limb by following a standardised program of keyboard and drum exercises [77]. MST includes necessary components for promoting motor learning such as mass repetition of movements, shaping, tailoring, task variability, instructional language and guidance by the therapist, modelling, and feedback [33]. Of particular relevance in MST is audio-motor coupling since individuals receive auditory feedback from the musical instrument that may help detect errors and adjust future movements [73]. Moreover, playing musical instruments is an activity that involves emotional and motivational aspects, which can boost motor learning and enhance emotional well-being [70, 88, 94].

Two recent randomised controlled trials have shown that MST can lead to similar motor improvements as with standard rehabilitation [28, 32]. A study of 20 chronic stroke patients also found that brain plastic changes can occur after MST in the form of cortical motor map reorganisation and enhanced functional coupling between motor and auditory regions [4, 71]. Furthermore, Grau-Sánchez et al. [32] showed that patients with higher sensitivity to music reward were the ones that showed greater motor improvements after MST, a finding that highlights the role of reward and motivation on learning during rehabilitation [1, 32, 63].

Despite these promising findings, the training protocol of MST has some limitations that have precluded widespread application in the chronic stage. First, MST is often delivered in the hospital or in rehabilitation centres; however, this form of delivery may not be the most suitable option for chronic patients. One of the aims of rehabilitation in the chronic phase is reintegration into community life and transitioning to home- and community-based programs can assist with such reintegration [65]. Second, studies investigating MST usually provide between 15 and 20 sessions of $30 \mathrm{~min}$ during over three or 4 weeks. This training intensity is not sufficient in the chronic phase, as training protocols need to be of higher intensity and longer duration to effectively promote recovery [20, 40, 41]. Third, only two musical instruments have been used: a keyboard and an electronic drum set, which allows training fine finger movements and gross arm movements. The use of other instruments might improve MST by providing a wider range of movements. Fourth, sessions are provided individually, which does not promote social interaction with other patients and lack a key components of musical activity, social bonding [19, 25, 60]. Especially in the chronic stage, patients with stroke often feel lonely and deprived of opportunities to engage in meaningful social activities $[37,56]$. Peer support is particularly relevant in rehabilitation since it can increase patients' quality of life [44]. Finally, sessions are therapist-led, which in the chronic stage, can diminish the patients' opportunities to engage in more self-regulated behaviours during their learning process [15]. According to recent theories of motor learning [93], optimization of learning is closely associated with social and intrinsic motivational factors. Therefore, interventions focused on strengthening motivational and self-control aspects could lead to greater recovery [21, 22, 48].

Considering the above constraints and taking into account previous experiences in adapting music interventions 
for home use [26, 87], we have designed a 10-week enriched MST (eMST) training program combining individual self-training sessions at home with online peergroup sessions. Compared to the standard MST program eMST features i) increased training intensity and range of movements trained; ii) inclusion of peer-group sessions; iii) optimisation of learning through enhanced intrinsic motivational factors to promote more autonomy; and iv) adaptation of the program for home use.

The program comprises 40 one-hour sessions $(40 \mathrm{~h}$ in total) distributed evenly over 10 weeks (4 sessions/week). We have also included additional percussion instruments to increase the range of movements that patients can train [70]. Considering that participation in social music activities is one of the most important sources of reward derived from music [52], we have included group sessions once a week to promote social interaction and group bonding [59, 82]. The self-training sessions are delivered at home using an electronic tablet, a keyboard and a set of percussion instruments. We have designed an artificial intelligence (AI) platform taking into account recent theories of motor learning to optimise the learning process by boosting intrinsic motivational factors. In the sessions at home, patients are given opportunities to have more control of their behaviours during the training, which can have a significant impact on feelings of self-competence and autonomy. Moreover, the AI platform uses elements of gamification and continuously monitors the patient's performance and supports therapists in the design and personalization of training sessions by using prediction and prescription components [75]. The adaptation of the program for home use may serve to increase motivation and reward derived from music, facilitate learning through self-controlled training and feedback, and enhance mood and quality of life by improving self-esteem, competence and autonomy.

This parallel-group randomised controlled trial will test the effectiveness of eMST in improving upper extremity motor function in chronic stroke patients when compared to a validated program of home-based exercises. Secondary objectives include testing the effectiveness of this intervention in enhancing cognitive outcomes, emotional well-being, quality of life, and self-regulation and efficacy and compare the effects of this intervention to a conventional home-based program of upper extremity exercises. We hypothesize that eMST will lead to larger motor and cognitive improvements, and enhanced emotional well-being and quality of life compared with home-based physical exercises alone.

\section{Methods}

\section{Study design}

A parallel-group randomised controlled trial will be conducted with participants being randomised to either eMST (eMST-group) or to a control treatment (CT-group), the latter receiving the Graded Repetitive Arm Supplementary Program (GRASP, [36]). The control treatment has already been validated and proven to be effective in enhancing the motor function of the upper extremity in chronic stroke patients [18, 28, 36].

Both interventions will comprise of 40 one-hour sessions distributed over 10 weeks (4 sessions per week, $40 \mathrm{~h}$ in total). Before and after the treatment, both groups will undergo an evaluation of their motor and cognitive function, emotional well-being and quality of life. A follow-up assessment will be conducted at 3 months (Fig. 1).

\section{Participants}

Chronic stroke patients will be recruited from two tertiary hospitals of the Barcelona metropolitan area (Hospitals del Mar i l'Esperança and Bellvitge University Hospital). These hospitals have stroke units and specialised inpatient and outpatient neurological rehabilitation departments.

Patients diagnosed with ischemic or haemorrhagic stroke will be eligible as participants if they fulfil the following criteria: presence of mild-to-moderate paresis of the upper extremity after a stroke defined as having a score between 1 and 4 in the Medical Research Council Scale for Muscle Strength at the distal upper limb muscles; more than 6 months post-stroke; completion of formal rehabilitation programs; no major language or cognitive deficits affecting comprehension (Montreal Cognitive Evaluation $\geq 26$ ); no neurological or psychiatric co-morbidity; and no other musculoskeletal condition affecting upper extremity motor function (e.g. fracture or arthritis).

Two clinical researchers will review medical records of stroke patients who had been treated in the rehabilitation departments of the recruiting hospitals. Phone contacts will be made to screen for potential participants followed by an appointment to evaluate if the patient fulfils the inclusion criteria. Patients will receive a detailed explanation of the procedures of the study and will provide written informed consent prior to participation.

\section{Experimental treatment: enriched music-supported therapy program}

Participants in the eMST-group will follow a 10-week intervention that will consist of 4 weekly one-hour sessions (total program duration: $40 \mathrm{~h}$ ). The training program comprises three individual home-based selftraining sessions and one group session per week.

\section{Individual home-based self-training sessions}

The individual sessions at home are delivered using an app on electronic tablets, which provides instructions and cues for patients, records the patient's performance and gathers data about exercises and compliance. At the 


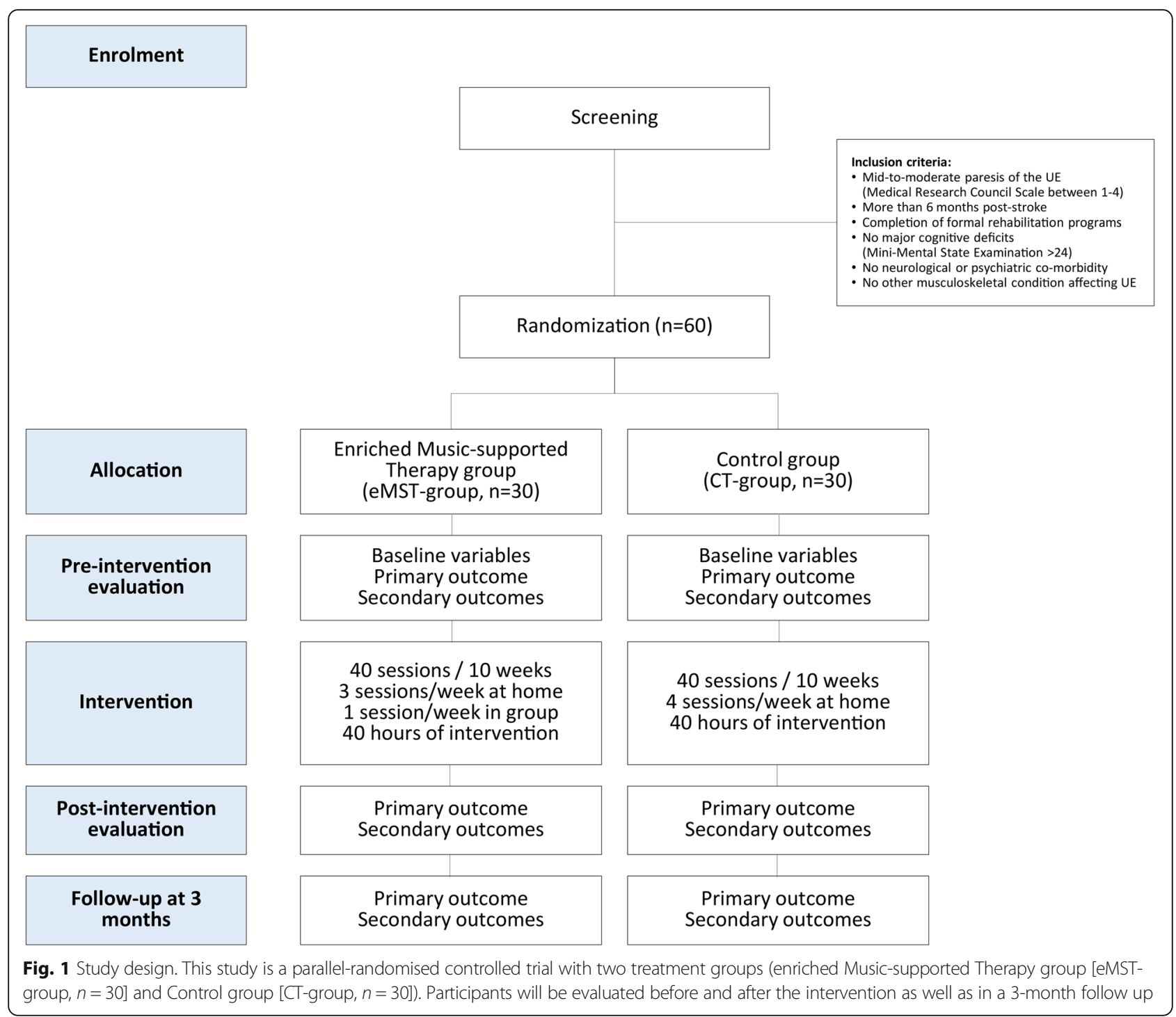

beginning of the intervention program, a therapist visits the patient's home to provide the materials for treatment and instructions on the app for home use. The participant is provided with percussion musical instruments (Table 1), an electronic keyboard and an electronic tablet. In each session, the participant is asked to play four percussion instruments and the electronic keyboard to train gross and fine mobility, respectively. Table 1 describes the different movements that can be trained with each instrument. Each individual session has the same fixed structure (described in Fig. 2) starting with percussion exercises as a warm-up and as a form of gross and fine mobility training (20 min), followed by keyboard exercises to train fine movements $(20 \mathrm{~min})$, an evaluation of the motor performance and finally, play musical games $(15 \mathrm{~min})$. Mood is evaluated at the end of each session ( $5 \mathrm{~min})$.
Percussion exercises In each session, the participant is presented with an image of four different percussion instruments and can select the order in which she / he would like to play them. For each exercise, the app first displays a short video demonstrating how to play the particular instrument and provides instructions to avoid compensatory movements (Fig. 3a). Then, the participant is instructed to play the instrument following a rhythmic pattern as shown on the tablet. The patient is asked to listen to the rhythmic pattern for later imitation. A visual cue provides a countdown to ensure the readiness of the patient. Then, the patient is asked to reproduce the pattern following auditory and visual cues. Table 2 describes the rhythmic patterns of the percussion exercises, which are graded by difficulty. The different movements, rhythmic patterns and tempo involved in the percussion exercises are presented in Table 3. 
Table 1 Manual for therapists enriched Music-Supported Therapy: Instruments and movements. This table provides information about the different movements that can be trained with each instrument. For sitting exercises the patient must be seated in a chair without armrests in a comfortable position with both knees and hip at $90^{\circ}$. For standing exercises the patient must be standing up having the chair at their back and with feet slightly separated

\begin{tabular}{llll}
\hline Instrument & Type of movement & Body position & Movement description \\
\hline $\begin{array}{l}\text { Tambourine } \\
\text { with beater }\end{array}$ & $\begin{array}{l}\text { Shoulder flexion/ } \\
\text { extension }\left(\text { shoulder at } 90^{\circ}\right.\end{array}$ & $\begin{array}{l}\text { Sitting/Standing } \\
\left.\text { and elbow at } 0^{\circ}\right)\end{array}$ & $\begin{array}{l}\text { Position: Hold the tambourine with the unaffected extremity } \\
\text { and the beater with the affected extremity. Both shoulders } \\
\text { should be at } 90^{\circ} \text { with the elbows at } 0^{\circ} . \\
\text { Movement: Hit the tambourine with the beater trying to keep } \\
\text { the elbow at } 0^{\circ} \text { to produce movements of shoulder flexion and }\end{array}$
\end{tabular}
extension.

Shoulder internal/external Sitting/Standing rotation and elbow flexion/extension (elbow at $\left.90^{\circ}\right)$

Wrist flexion/extension (shoulder at $0^{\circ}$ and elbow at $90^{\circ}$ )

Tambourine

Shoulder abduction/ adduction (elbow at $0^{\circ}$ )

Standing

Shoulder abduction/ adduction (elbow at $0^{\circ}$ )

Standing

Wrist flexion/extension

(shoulder at $0^{\circ}$ and elbow at $0^{\circ}$ )

Forearm supination/ pronation (shoulder at $0^{\circ}$ and elbow at $90^{\circ}$ )

Forearm supination/ pronation (shoulder at $90^{\circ}$ and elbow at $0^{\circ}$ )

Maracas

Elbow flexion/extension (shoulder at $0^{\circ}$ )

Wrist flexion/extension

(shoulder at $0^{\circ}$ and elbow at $90^{\circ}$ )

Güiro

Elbow flexion/extension (no gravity)

Rainstick

Forearm supination/ pronation (shoulder at $90^{\circ}$ and elbow at $0^{\circ}$ )

Egg Shaker
Standing

Sitting/Standing

Sitting/Standing

Sitting/Standing

Sitting/Standing

Sitting

Sitting/Standing

Sitting/Standing
Elbow flexion/extension (shoulder at $0^{\circ}$ )
Position: Hold the tambourine with the unaffected extremity and the beater with the affected extremity. Movement: Hit the tambourine with the beater to produce movements of elbow flexion and extension.

Position: Hold the tambourine with the unaffected extremity and the beater with the affected extremity.

Movement: Hit the tambourine with the beater trying to keep the elbow at $90^{\circ}$ to produce movements of wrist flexion and extension.

Position: Hold the tambourine with the affected extremity. Standing up, extremities should drop on either side of the body. Movement: Hit the tambourine in the side of your leg trying to keep the elbow at $0^{\circ}$ to produce movements of shoulder abduction/adduction.

Position: Hold the tambourine with the affected extremity. Standing up, extremities should drop on either side of the boy. Movement: Hit the tambourine in the front of your leg trying to keep the elbow at $0^{\circ}$ to produce movements of shoulder abduction/adduction.

Position: Hold the tambourine with the affected extremity. Standing up, extremities should drop on either side of the body. Movement: Hit the tambourine in the side of your leg trying to keep the elbow at $0^{\circ}$ to produce movements of wrist flexion/ extension.

Position: Hold the tambourine with the affected extremity. The shoulder should be at $0^{\circ}$ and elbow at $90^{\circ}$.

Movement: Turn your forearm up and down trying to keep the elbow at $90^{\circ}$.

Position: Hold the tambourine with the affected extremity. Hold the tambourine with the affected extremity. The shoulder should be at $90^{\circ}$ and elbow at $0^{\circ}$.

Movement: Turn your forearm up and down trying to keep the elbow at $0^{\circ}$.

Position: Hold a maraca with the affected extremity.

Movement: Starting with the elbow at $90^{\circ}$, shake the maraca to produce movements of elbow flexion and extension.

Position: Hold a maraca with the affected extremity. Movement: Shake the maraca to produce movements of wrist flexion and extension trying to keep the elbow at $90^{\circ}$.

Position: Hold the güiro with the unaffected extremity and the stick with the affected extremity. The güiro can rest over the knees and both elbows should be at $0^{\circ}$ of flexion.

Movement: Rub the sick along the notches of the güiro.

Position: Hold the rainstick with the affected extremity. The shoulder should be at $90^{\circ}$ with the elbow at $0^{\circ}$.

Movement: Turn your forearm up and down.

Position: Hold the egg shaker with the affected extremity. The shoulder should be at $0^{\circ}$ and the elbow at $90^{\circ}$.

Movement: Starting with the elbow at $90^{\circ}$, shake the egg to produce movements of elbow flexion and extension. 
Table 1 Manual for therapists enriched Music-Supported Therapy: Instruments and movements. This table provides information about the different movements that can be trained with each instrument. For sitting exercises the patient must be seated in a chair without armrests in a comfortable position with both knees and hip at $90^{\circ}$. For standing exercises the patient must be standing up having the chair at their back and with feet slightly separated (Continued)

\begin{tabular}{|c|c|c|c|}
\hline Instrument & Type of movement & Body position & Movement description \\
\hline & $\begin{array}{l}\text { Elbow flexion/extension } \\
\text { (no gravity) }\end{array}$ & Sitting/Standing & $\begin{array}{l}\text { Position: Hold the egg shaker with the affected extremity. } \\
\text { Movement: Shake the egg side to side. }\end{array}$ \\
\hline & $\begin{array}{l}\text { Wrist flexion/extension } \\
\left(\text { shoulder at } 0^{\circ} \text { and elbow }\right. \\
\left.\text { at } 90^{\circ}\right)\end{array}$ & Sitting/Standing & $\begin{array}{l}\text { Position: Hold the egg shaker with the affected extremity. The } \\
\text { shoulder should be at } 0^{\circ} \text { and the elbow at } 90^{\circ} \text {. } \\
\text { Movement: Shake the egg up and down trying to keep the } \\
\text { elbow at } 90^{\circ} \text { to produce movements of wrist flexion and } \\
\text { extension. }\end{array}$ \\
\hline Castanets & $\begin{array}{l}\text { Fingers mass flexion/ } \\
\text { extension (shoulder at } 0^{\circ} \\
\text { and elbow at } 90^{\circ} \text { ) }\end{array}$ & Sitting & $\begin{array}{l}\text { Position: Hold a castanet with the affected extremity, leaving } \\
\text { the castanet resting on the palm. The elbow should be at } 90^{\circ} \text { of } \\
\text { flexion and shoulder at } 0^{\circ} \text { of flexion. } \\
\text { Movement: Press the castanet with the fingers to produce } \\
\text { movements of finger mass flexion and extension. }\end{array}$ \\
\hline \multirow[t]{2}{*}{ Djembe } & $\begin{array}{l}\text { Wrist flexion/extension } \\
\text { (shoulder at } 0^{\circ} \text { and elbow } \\
\text { at } 90^{\circ} \text { ) }\end{array}$ & Sitting & $\begin{array}{l}\text { Position: Hold the djembe with the nonaffected extremity and } \\
\text { lean it between your knees. The shoulder should be at } 0^{\circ} \text { and } \\
\text { the elbow at } 90^{\circ} \text {. } \\
\text { Movement: Hit the djembe with the affected hand trying to } \\
\text { keep the elbow at } 90^{\circ} \text { to produce movements of wrist flexion } \\
\text { and extension. }\end{array}$ \\
\hline & $\begin{array}{l}\text { Elbow flexion/extension } \\
\text { (shoulder at } 0^{\circ} \text { and elbow } \\
\text { at } 90^{\circ} \text { ) }\end{array}$ & Sitting & $\begin{array}{l}\text { Position: Hold the djembe with the nonaffected extremity and } \\
\text { lean it between your knees. The shoulder should be at } 0^{\circ} \text { and } \\
\text { the elbow at } 90^{\circ} \text {. } \\
\text { Movement: Hit the djembe with the affected hand trying to } \\
\text { shoulder at } 0^{\circ} \text { to produce movements of elbow flexion and } \\
\text { extension. }\end{array}$ \\
\hline
\end{tabular}

Keyboard exercises For the exercises with the keyboard, participants are asked to play simple sequences that gradually increase in difficulty (Fig. 3b). The app provides visual instructions as well as cues to prompt finger movements and records the performance of the patient with the keyboard. Exercises with the keyboard increase in difficulty depending on the patient's progress. During each exercise, different types of feedback encourage the participant to play as well as they can. A vertical score bar on the right side of the screen with a star on the top fills up as the participant plays the notes correctly. In addition playing an incorrect note causes the screen to turn red so that the participants can realize their mistake and play the correct note.
Games Participants have the possibility to play musical games, an optional part of the treatment they can skip if they are tired or not in the mood to play. They can choose between four different games: 1) Simon says, comprising the participant is asked to repeat a sequence that is presented, which becomes progressively longer and more complex as she / he succeeds; 2) Piano Hero, notes scroll on-screen to the different keys and participants have to play in time to score points; 3) Combo, the participant plays along songs that are rehearsed during the group sessions by accompanying the melody with the keyboard and/or using the percussion instruments; and 4) Impro, the participant improvises freely on the keyboard.

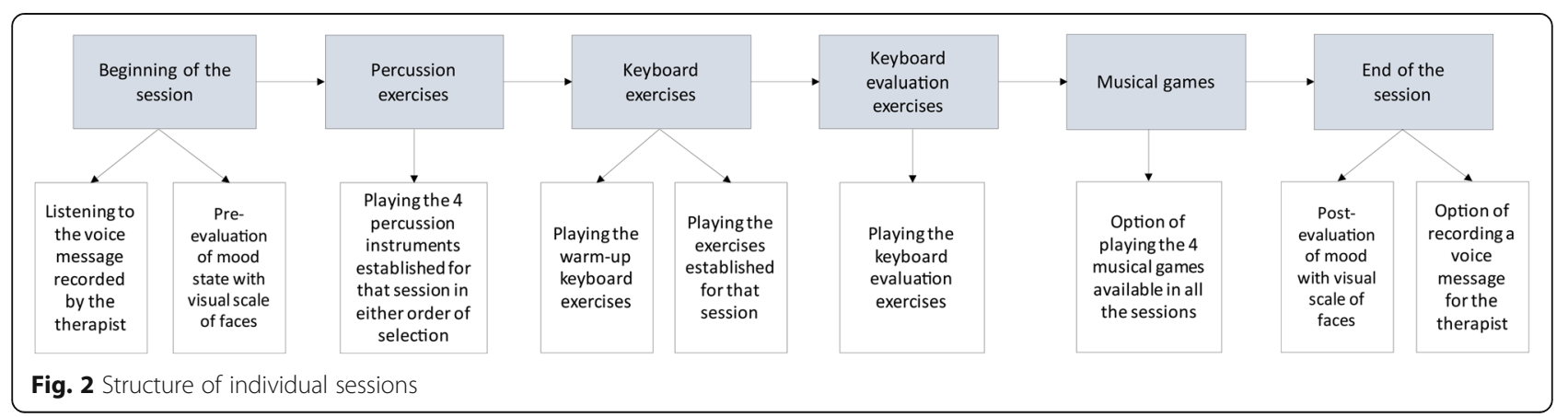




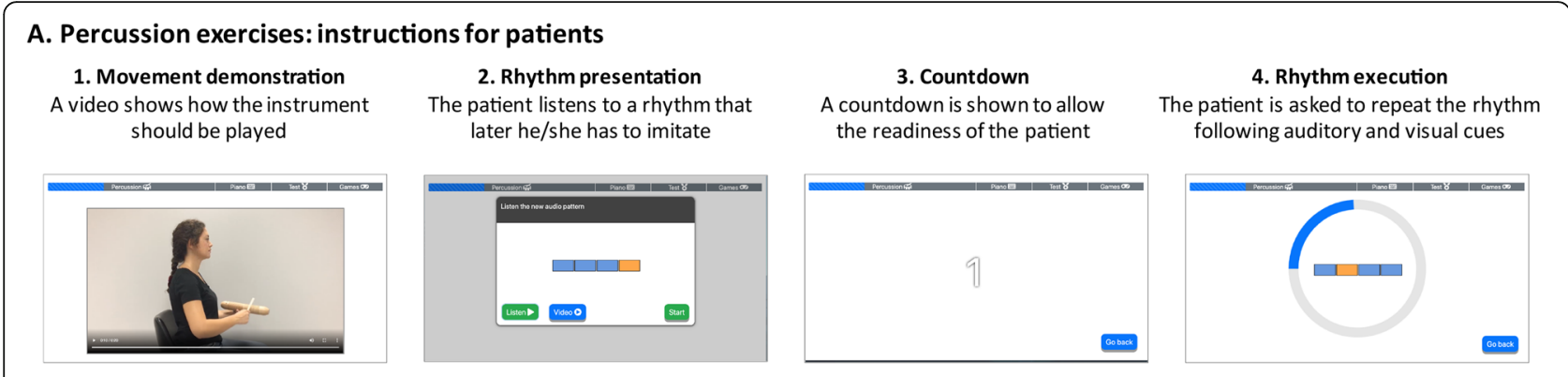

B. Keyboard exercises: instructions for patients

1. Indication of the hand

The affected hand is shown to allow the readiness of the patient

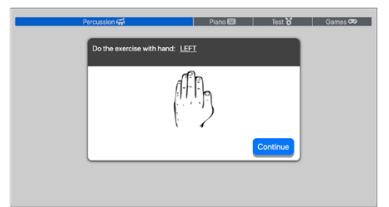

2. Finger/s instruction

An image shows the finger/s with which the patient is asked to do the exercise

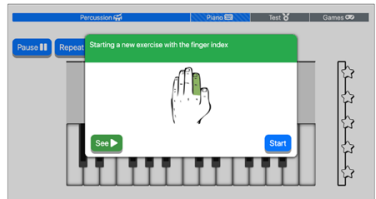

3. Sequence demonstration

4. Patient's performance and recording the paws the sequence of note

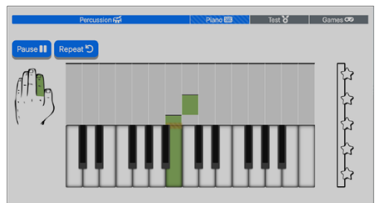

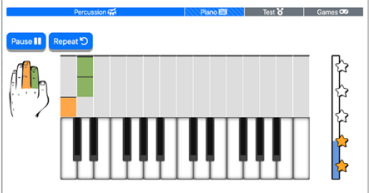

Fig. 3 Percussion and keyboard exercises for the home-based individual sessions. a Percussion exercises: instructions for patients. First, there is a video to instruct how the instrument should be played (1) followed by the presentation of the rhythmic pattern (2). After a visual countdown (3), the patient has to reproduce the rhythm with the instrument (4). b Piano exercises: instructions for patients. A drawing of the affected hand is shown (1) followed by a cue that indicates the finger/s that should be used in the exercise (2). After a short clip showing the sequence of notes to be played (3) the patient has to play the keyboard following visual cues (4)

Monitoring The keyboard is connected to the electronic tablet as a midi-device, which allows recording the played notes, any errors made, key-pressure and the execution time for each exercise. The AI platform is based on three main components (visualisation,

Table 2 Rhythmic patterns. This table provides the different rhythmic patterns that are asked to play in the home-based MST sessions with different percussion instruments

\section{Rhythmic patterns}

Level 1

Level 2

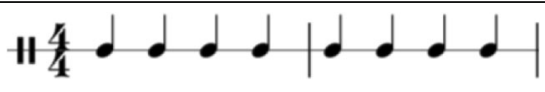

Level 3

Level 4
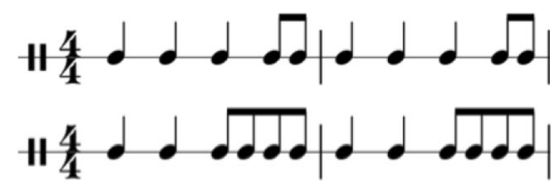

Level 5

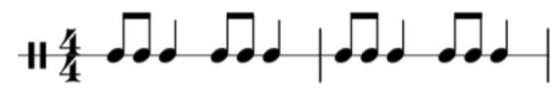

Level 6

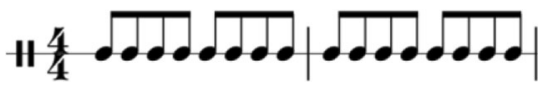

Level 7

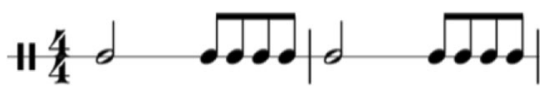

Level 7

Level 8
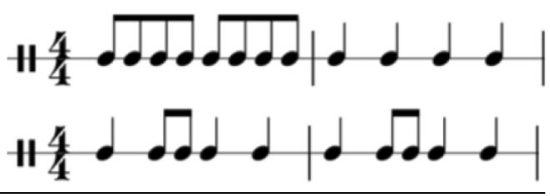

prediction, and prescription). All the information is processed to visually summarise the performance of the patient. To tailor the intervention to the individual needs of the patient, the therapist can virtually prescribe exercises and instruments to be used for each session. The prediction component computes an initial performance estimation based on baseline assessments. The prescription component recommends appropriate exercises to the therapist by taking into account the performance of the patient and adjusting them for difficulty. Since the percussion instruments have no sensors, the AI platform only gathers data related to the interaction with the app (watching the video, listening to the rhythm, and starting the exercise).

Daily evaluation At the end of the home-based sessions the motor performance and the mood of the participants are evaluated. Five keyboard exercises of 3-5 min duration are applied ranging in difficulty from playing simple sequences with one finger to playing complex sequences with five fingers. Moreover, participants are asked to rate their mood on a visual scale of emotional faces (from $1=I$ am feeling very bad to $5=I$ am feeling very good). Participants can also record a voice message for the therapist. The therapist's response is shown at the beginning of the following session. 


\section{Group sessions}

Once per week a one-hour virtual group session of music therapy will be conducted using a video communication platform that is installed in the electronic tablet provided to participants. Participants will be split into groups of 34 people for the group sessions. A music therapist and an occupational therapist will conduct the group sessions, providing instructions for the music therapy exercises. The sessions involve active and passive music therapy exercises structured into three parts: 1) Beginning, featuring warming-up exercises; 2) Core, comprising musical improvisation and playing of favourite songs; and 3) Ending, featuring relaxation exercises. All the exercises will be accompanied by live music with the music therapist playing along on the piano or guitar. Participants will be asked to play musical instruments during the sessions to train gross and fine motor skills, but they can select the musical instruments they wish to play from many different percussion instruments. Participants will be encouraged to play with the affected extremity to showcase what they have learned during their individual sessions. At the beginning and the end of the session, therapists will facilitate a discussion where patients can share their progress, difficulties and worries. The selection of songs for the group sessions is done with the participants, taking into account their musical preferences. For this reason, a semistructured interview will be conducted at the beginning of the intervention program to understand cultural preferences, professional and leisure activities, musical knowledge and previous musical experience and preferences.

Daily evaluation At the end of the group session, each participant will be asked to answer the Participant PostSession Questionnaire, consisting of 4 short questions about the feelings of connection to music and the people in the group on a 4-point Likert scale. Moreover, the therapists evaluate the overall performance of each patient as well as their engagement in music making using the 9-point Music Engagement Scale adapted from the Music Therapy Communication and Social Interaction scale (MTCSI; [13]). Each participant is also asked to rate the social connectedness with others following the Inclusion of Other in the Self Scale [6], and participants have to rate their mood using a visual scale of emotional faces (from $1=I$ am feeling very bad to $5=I$ am feeling very good).

\section{Control treatment: GRASP}

Participants in the control intervention group will follow the Graded Repetitive Arm Supplementary Program (GRASP, [36]). This program consists of self-directed arm and hand exercises for stroke patients and it is validated to be performed by patients on their own at home. GRASP seeks to promote hand and arm motor function recovery through mass repetition of movements and

Table 3 Percussion exercises. For each percussion exercise, the movements involved, and the rhytmic pattern and tempo that can be asked to the participant is presented

\begin{tabular}{|c|c|c|c|}
\hline Instrument & Movement & Rhythmic patterns & Tempo \\
\hline \multirow[t]{3}{*}{ Tambourine with beater } & Shoulder flexion/extension (shoulder at $90^{\circ}$ and elbow at $0^{\circ}$ ) & $1,2,3$ & 30 \\
\hline & $\begin{array}{l}\text { Shoulder internal/external rotation and elbow flexion/extension } \\
\text { (elbow at } 90^{\circ} \text { ) }\end{array}$ & $1,2,3,4,7,8$ & 40 \\
\hline & Wrist flexion/extension (shoulder at $0^{\circ}$ and elbow at $0^{\circ}$ ) & $1,2,3,4,5,6,7,8$ & 60 \\
\hline \multirow[t]{5}{*}{ Tambourine } & Shoulder abduction/adduction (elbow at $0^{\circ}$ ) & $1,2,3$ & 30 \\
\hline & Shoulder abduction/adduction (elbow at $0^{\circ}$ ) & $1,2,3$ & 30 \\
\hline & Wrist flexion/extension (shoulder at $0^{\circ}$ and elbow at $0^{\circ}$ ) & $1,2,3,4,5,6,7,8$ & 60 \\
\hline & Forearm supination/pronation (shoulder at $0^{\circ}$ and elbow at $90^{\circ}$ ) & $1,2,3,4,5,6,7,8$ & 60 \\
\hline & Forearm supination/pronation (shoulder at $90^{\circ}$ and elbow at $0^{\circ}$ ) & $1,2,3,4,5,6,7,8$ & 60 \\
\hline \multirow[t]{2}{*}{ Maracas } & Elbow flexion/extension (shoulder at $0^{\circ}$ ) & $1,2,3,4,6,8$ & 50 \\
\hline & Wrist flexion/extension (shoulder at $0^{\circ}$ and elbow at $90^{\circ}$ ) & $1,2,3,4,5,6,7,8$ & 60 \\
\hline Güiro & Elbow flexion/extension (no gravity) & $1,2,3,4,5,6,7,8$ & 60 \\
\hline Rainstick* & Forearm supination/pronation (shoulder at $90^{\circ}$ and elbow at $0^{\circ}$ ) & - & - \\
\hline \multirow[t]{3}{*}{ Egg Shaker } & Elbow flexion/extension (shoulder at $0^{\circ}$ ) & $1,2,3,4,6,8$ & 50 \\
\hline & Elbow flexion/extension (no gravity) & $1,2,3,4,5,6,7,8$ & 60 \\
\hline & Wrist flexion/extension (shoulder at $0^{\circ}$ and elbow at $90^{\circ}$ ) & $1,2,3,4,5,6,7,8$ & 60 \\
\hline Castanets & Fingers mass flexion/extension (shoulder at $0^{\circ}$ and elbow at $90^{\circ}$ ) & $1,2,3,4,5,7,8$ & 60,70 \\
\hline \multirow[t]{2}{*}{ Djembe } & Wrist flexion/extension (shoulder at $0^{\circ}$ and elbow at $90^{\circ}$ ) & $1,2,3,4,5,6,7,8$ & 60,70 \\
\hline & Elbow flexion/extension (shoulder at $0^{\circ}$ and elbow at $90^{\circ}$ ) & $1,2,3,4,5,6,7,8$ & 50 \\
\hline
\end{tabular}


task-specific exercises, encouraging the use of the affected extremity in everyday activities. Participants will be asked to complete 4 weekly one-hour session for 10 weeks (total program duration: $40 \mathrm{~h}$ ).

A booklet describing the exercises and the equipment needed will be provided to participants. Exercises involve arm and hand strengthening, coordination and manual skills using everyday objects (e.g., toothpicks, Lego bricks, clothespins or paper clips). The participant will be asked to perform the exercises sitting in a chair or next to a table in sets of 5 or 10 repetitions. The number of sets and the exercises prescription will be adjusted to the patient's needs and endurance.

At the beginning of the intervention, the therapist will visit the participant's home to provide instructions and equipment to follow the program. Patients will be asked to register the type and amount of exercises for each session on a record sheet. Moreover, after each session, participants will be asked to rate their mood using a visual scale of emotional faces (from $1=I$ am feeling very bad to $5=I$ am feeling very good). The therapist will contact the participant by phone once a week to monitor her/his progress and difficulties.

\section{Treatment compliance and withdrawal}

Completion of intervention protocol would require the patient to perform $\geq 80 \%$ of the sessions.

\section{Evaluation}

An initial evaluation will include the collection of demographical and clinical variables will be performed at baseline. In addition, primary and secondary motor, cognitive and emotional well-being and quality of life outcomes will be evaluated before and after the intervention as well as at 3-month follow-up. Table 4 summarises the variables and outcomes of the study. Considering the current health crisis due to the COVID-19 pandemic, the evaluation will be carried out at the participant's home in order to avoid unnecessary visits to the hospital.

\section{Baseline demographic and clinical variables}

Demographic and clinical variables such as age, gender, level of education, living situation, previous musical training, stroke aetiology and location, and lesion laterality will be collected from medical records as well as during a first interview with the participant.

In order to characterise individual differences that can have a mediating effect on treatment success, we will evaluate cognitive functions, differences in the processing and integration of music, music reward, perseverance and social support at the beginning of the intervention. Therefore, the baseline evaluation will include the Spanish version of the Montreal Cognitive Assessment [45, 62] to assess global cognitive function, the digit span (included in the Wechsler Adult Intelligence Scale, WAIS-IV, [97]; adapted to Spanish by Pearson Clinical \& Talent Assessment) to assess working memory, a short version of the Boston Naming Test validated in Spanish [14, 47] to assess language production, and the vocabulary subtest of the WAIS-IV. In addition, the scale and rhythm subtests from the shortened version of the Montreal Battery of Evaluation of Amusia [68] will be used to screen for amusia at baseline. Participants will complete the Barcelona Music Reward Questionnaire ([51], validated in Spanish) on the first evaluation to assess individual differences in pleasure derived from musical experiences. Finally, individual differences in perseverance and passion for long-term goals will be assessed with the Grit Scale ([23]; validated in Spanish in [9]), and social support will be assessed using the Spanish version of the Multidimensional Scale of Perceived Social Support $([43,95])$.

\section{Primary outcome}

The primary outcome will be upper extremity function measured with the Action Research Arm Test (ARAT, [46]). The ARAT is recommended for use in chronic stroke and outpatient rehabilitation by the StrokeEDGE Task Force Group [81] and has excellent test-retest and inter/intra-rater reliability $[69,85]$. The measure is a 19 item test divided into four subtests (grasp, grip, pinch and gross movement). For each item, the patient is asked to perform a simple task that involves a functional movement of the affected upper limb. Each task is rated using a 4-point ordinal scale. The maximum possible score is 57 and the minimal clinically important difference is 5.7 points [84].

\section{Secondary outcomes}

Motor outcomes The upper extremity subtest of the Fugl-Meyer Assessment of Motor Recovery after Stroke (FMA [27];) will be used to evaluate motor impairment; grip strength will be assessed with a dynamometer and functional movements and dexterity will be assessed with the Box and Block Test [53] and the Nine Hole Pegboard Test [66]. The Chedoke Arm and Hand Activity Inventory will be used to evaluate the patients' motor performance in everyday tasks [7].

The upper extremity subtest of the FMA comprises 33 items that evaluate motor impairment in the affected upper limb. The test is divided into 4 sections (shoulder, forearm and elbow, wrist, hand and coordination) assessing reflexes, flexor and extensor synergies, range of motion, and overall coordination and speed of the upper extremity. Each item is graded using an ordinal scale from 0 to 2 . The maximum possible score is 66 and the minimal clinically important difference for chronic stroke patients is 5.2 points [64]. 
Table 4 Variables and outcomes of the study

\begin{tabular}{|c|c|c|c|c|}
\hline Instrument & Reference & Baseline & Post-intervention & Follow-up \\
\hline \multicolumn{5}{|l|}{ Demographic and clinical variables } \\
\hline Montreal Cognitive Assessment & [62] & $\cdot$ & & \\
\hline Digit span subtest & [97] & $\cdot$ & & \\
\hline Boston Naming Test, short form & [47] & $\cdot$ & & \\
\hline Vocabulary subtest & [97] & $\cdot$ & & \\
\hline $\begin{array}{l}\text { Scale and rhythm subtests Montreal Battery of Evaluation } \\
\text { of Amusia }\end{array}$ & [68] & $\cdot$ & & \\
\hline Barcelona Music Reward Questionnaire & [51] & $\cdot$ & & \\
\hline Grit scale & [23] & $\cdot$ & & \\
\hline Multidimensional Scale of Perceived Social Support & [95] & $\cdot$ & & \\
\hline \multicolumn{5}{|l|}{ Primary outcome } \\
\hline Action Research Arm Test & [46] & $\cdot$ & $\cdot$ & $\cdot$ \\
\hline \multicolumn{5}{|l|}{ Secondary motor outcomes } \\
\hline Fugl-Meyer Assessment of Motor Recovery after Stroke & [27] & $\cdot$ & $\cdot$ & $\cdot$ \\
\hline Grip strength & [54] & $\cdot$ & · & $\cdot$ \\
\hline Box and Block Test & [53] & $\cdot$ & $\cdot$ & $\cdot$ \\
\hline Nine Hole Pegboard Test & [66] & $\cdot$ & $\cdot$ & $\cdot$ \\
\hline Chedoke Arm and Hand Activity Inventory & [7] & $\cdot$ & $\cdot$ & $\cdot$ \\
\hline Secondary cognitive outcomes & & · & · & $\cdot$ \\
\hline Behaviour Rating Inventory of Executive Function & [74] & $\cdot$ & $\cdot$ & · \\
\hline Sustained Attention to Response Task & [72] & $\cdot$ & $\cdot$ & · \\
\hline Figural memory subtest & [90] & $\cdot$ & $\cdot$ & · \\
\hline Rey Auditory Verbal Learning Test & [74] & $\cdot$ & · & $\cdot$ \\
\hline Fluency test & [89] & $\cdot$ & $\cdot$ & $\cdot$ \\
\hline \multicolumn{5}{|l|}{$\begin{array}{l}\text { Secondary emotional well-being and quality of life } \\
\text { outcomes }\end{array}$} \\
\hline Beck Depression Inventory-II & [11] & · & · & . \\
\hline Apathy Evaluation Scale & [49] & $\cdot$ & $\cdot$ & $\cdot$ \\
\hline Profile of Mood States & [57] & $\cdot$ & $\cdot$ & $\cdot$ \\
\hline Stroke Impact Scale & [61] & $\cdot$ & $\cdot$ & $\cdot$ \\
\hline Self-regulation and self-efficacy outcomes & & \multicolumn{3}{|c|}{ During intervention } \\
\hline Treatment Self-regulation questionnaire & {$[80]$} & & $\cdot$ & \\
\hline Treatment Questionnaire Concerning Continued Program & {$[80]$} & & $\cdot$ & \\
\hline Intrinsic Motivation Inventory & [79] & & $\cdot$ & \\
\hline Strategies Used to Promote Health Questionnaire & [46] & & - & \\
\hline
\end{tabular}

The grip strength will be measured for both hands as the mean of three consecutive trials [54].

The Box and Block Test assesses gross manual dexterity by using a setup consisting of a box with 2 compartments and wood cubes. The participant is asked to grasp cubes and transport them from one compartment to the other. The number of cubes successfully transported within 1 minute is scored for the affected and the unaffected extremity. The minimal detectable change for the Box and Block Test is 5.5 cubes (H. M [16].).
The Nine Hole Pegboard Test evaluates fine dexterity by asking the patient to pick up nine pegs and place them into holes on a board and then remove them. The patient is asked to complete this task as fast as possible and the time needed is scored for the affected and the unaffected hand. The minimal detectable change for this test is $32.8 \mathrm{~s}$ (H. M [16].).

The Chedoke Arm and Hand Activity Inventory is a performance test that measures the patient's ability to perform everyday tasks with both extremities. The test is composed of 13 different tasks (i.e. open a jar of coffee, 
make a phone call, clean a pair of eyeglasses) and each task is graded using an ordinal scale from 1 to 7 . The scores are given based on the involvement of the affected extremity in the task, ranging from less than $25 \%$ of involvement in the task needing total assistance to complete independence in the task (adequate time and safety). The minimal clinically importance difference is 6.3 points [8].

Cognitive outcomes The neuropsychological evaluation will focus on assessing executive function, attention, visuospatial memory and verbal learning, and fluency. Executive function will be evaluated using the Behaviour Rating Inventory of Executive Function (BRIEF, [74]; validated in Spanish in [10]). The Sustained Attention to Response Task [72] will be used to assess sustained attention whereas the Figural Memory subtest from the Wechsler Memory Scale-Revised ([90]; adapted to Spanish by Pearson Clinical \& Talent Assessment) will evaluate visuospatial memory. Verbal learning will be evaluated using the Spanish version of the Rey Auditory Verbal Learning Test [50] and a fluency test in Spanish [67] will be used to examine verbal fluency.

The adult version of the BRIEF is a self-report questionnaire that evaluates executive functioning in everyday life situations. The questionnaire includes a self and informant reports. Both versions comprise 75 items describing various behaviours, and the participant is asked to report if the behaviour is never a problem, sometimes a problem or often a problem. The BRIEF provides two broad indexes (behavioral regulation and metacognition) as well as an overall score. It includes nine scales that assess the ability to inhibit, self-monitor, plan/organize, shift, initiate, task monitor, emotional control, working memory, and organization of materials.

The Sustained Attention to Response Task is a computerised test that evaluates sustained attention by presenting the participant with one number at a time and asking him or her to respond as fast as possible when a target number appears. This test provides measures of reaction times and changes on this variable over the task, as well as inhibition errors.

The Figural Memory subtest from the Wechsler Memory Scale-Revised [90] measures visuospatial recall and recognition memory. The participant is presented with abstracts designs that later he or she has to identify from an array.

The Rey Auditory Verbal Learning Test evaluates verbal learning by asking the patient to recall a list of 15 words. The list is presented 5 times and after each trial, the patient is asked to repeat as many words as he/she recalls. Then, a second list of words is presented as interference. The number of words recalled from the original list after the interference and after a break of 20 min is determined. A recognition test with distractors is also performed at the end of the test.

The verbal fluency test comprises two tasks: category and letter fluency. The participant is asked to produce as many words as possible for a minute of the same semantic category (i.e. animals) or words that start with the same letter (i.e. words starting with 'p'). The number of unique words produced is counted as the score for each task.

\section{Emotional well-being and quality of life outcomes} The emotional well-being evaluation will assess depression with the Spanish version of the Beck Depression Inventory-II [11, 76], apathy with the Apathy Evaluation Scale translated to Spanish [49] and mood with the Profile of Mood States ([57]; Spanish version by [5]). Healthrelated quality of life will be measured with the Stroke Impact Scale, which has been translated to Spanish for this study [61].

The Beck Depression Inventory-II is a self-report measure that comprises 21 multiple-choice questions that are scored on a scale from 0 to 3 . The participant is asked about feelings, thoughts and behaviours of the past week. Higher scores indicate depression severity and the maximum possible score of the measure is 63 .

The Apathy Evaluation Scale evaluates behavioural, cognitive and emotional indicators of apathy. The scale comprises a self and informant reports both consisting of 18 items that are scored on a 4-point Likert scale, where higher scores indicate more apathy.

The Profile of Mood States evaluates different dimensions of mood by asking the participant to rate feelings or emotion felt during the past week. The measure includes 65 items that are scored on a 5-point Likert scale ranging from 0 "not at all" to 4 "extremely".

The Stroke Impact Scale is a 59-item self-report questionnaire that assesses muscle strength, hand function, basic and instrumental activities of daily living, global mobility, communication, emotion, memory and thinking, and participation.

Self-regulation and self-efficacy outcomes Domainspecific individual differences in motivation and selfregulation for joining, participating in and engagement during the rehabilitation program will be assessed with the Treatment Self-Regulation Questionnaire (adapted from: [80]), the Treatment Questionnaire Concerning Continued Program Participation (adapted from: [80]), and the Intrinsic Motivation Inventory [79], respectively. Self-efficacy will be measured with the Strategies Used by People to Promote Health questionnaire [46]. These questionnaires have been translated to Spanish for the purpose of the study.

The Treatment Self-Regulation Questionnaire is an adaptation of the standard version called Academic Self- 
Regulation Questionnaire (SRQ-A) [80] created for the study. It evaluates the type of self-regulation (external, interjected, identified or intrinsic) or motivation (external or intrinsic) of the participants to engage with the rehabilitation program. It is a 15-item self-report questionnaire scored on a 7-point scale (1: not all true; 4: somewhat true; 7: very true). The items are questions about the reasons why the participants enrolled in the current study. Thus, the participants will be asked to answer it only at the beginning of the intervention.

The Treatment Questionnaire Concerning Continued Program Participation evaluates the type of self-regulation or motivation of the participants for continuing to participate in the rehabilitation program to which they have been assigned. It is a 15-item self-report questionnaire scored on a 7-point scale (1: not all true; 4: somewhat true; 7: very true). The items are questions about why the participants continue to engage with the rehabilitation program. Hence, the participants will be asked to complete it only in the middle of the intervention (the 5th week).

The Intrinsic Motivation Inventory is a multidimensional measure which assesses the content and level of motivation during an intervention. Therefore, participants will be asked to answer it only on completion of the rehabilitation program. The measure was adapted for the current study and consists of 24 self-report questions divided into six different psychological constructs reflecting positive or negative predictors of intrinsic motivation: 1) interest/enjoyment; 2) perceived competence; 3) effort/importance; 4) pressure/tension; 5) perceived choice; and 6) value/usefulness. It is scored on a 7-point scale (1: not all true; 4: somewhat true; 7: very true). The MST-group will complete 4 additional items on the psychological construct of relatedness in order to evaluate the effect of the group sessions on motivation levels.

The Strategies Used by People to Promote Health is a 29-item self-report questionnaire that evaluates the degree of self-care and self-efficacy through four factors consistent with the underlying self-efficacy theory upon which the scale is based: 1) coping, 2) stress reduction, 3) making decisions, and 4) enjoying life. It is scored on a 5-point scale (from 1: very little confidence to 5: quite a lot of confidence) and the participants will be asked to answer it in both pre- and post-intervention evaluations.

\section{Blinding}

A clinical researcher with expertise in stroke rehabilitation will perform the evaluations and will be blinded to participants' group allocation.

\section{Randomisation}

Participants will be randomised to one of the groups following a block randomisation procedure. As the
eMST program requires three participants for the group sessions, randomisation will consider clusters of three participants. The randomisation sequence will be computergenerated and only accessible to a research assistant who will not be involved in the recruitment, treatment or evaluation of participants. This research assistant will inform the therapists once the baseline evaluation of the participant is done.

\section{Ethical considerations and data management}

The protocol of this study has been approved by the Clinical Research Ethics Committee of the Bellvitge University Hospital (PR095/17; Barcelona, Spain) and the Hospitals del Mar i l'Esperança (Parc de Salut Mar, 2020/9523; Barcelona, Spain) and follows the Declaration of Helsinki to experiment with human beings. As mentioned previously, participants will be informed about study procedures and will sign an informed consent form prior to participation. Each participant will be identified with a code when collecting demographic and clinical variables and outcomes. All the information gathered by the app will be stored on an internal secure server from the Artificial Intelligence Research Institute, which is maintained by the IT team following institutional security standards. Additionally, patients are de-identified using the generated code. Connections between the tablet and server use a secure credential in an API Rest through a HTTPS protocol.

\section{Sample size}

The sample size calculation is based on a clinically relevant difference between treatment groups with $80 \%$ power and a $5 \%$ significance level. Considering that the minimal detectable change of the ARAT (primary outcome) is 5.7 points and that an acceptable difference between groups of $15 \%$ is defined to be clinically meaningful [84, 85], a sample size of 26 participants will be required in each group. From experience gathered in previous studies [32, 77], the dropout rate in this type of interventions is relatively low (15\%). Taking this rate into consideration, a final estimation of 60 participants is needed in the study, 30 per group.

\section{Data analysis}

Statistical analysis will be performed using $R$ ( $\mathrm{R}$ Core Team, 2019) and the Statistical Package for the Social Sciences (SPSS version 21, SPSS inc., Chicago, Illinois, USA). For descriptive analyses, quantitative data will be analysed using mean and standard deviation if the data is normally distributed and median and interquartile range will be used for variables that are not normally distributed. Qualitative variables will be presented using frequency distributions and percentages. 
An intention-to-treat analysis will be performed for all outcome variables including all patients that were assigned to a group and for whom the primary outcome was collected at baseline. In the case of participants that withdraw form the study, the score at baseline will be assigned for all the evaluation points and reasons for withdrawal will be reported.

The effect of the intervention on the primary outcome, the ARAT, will be assessed using the chi-square test. Taking into account the minimal clinically important difference of this test (5.7 points) data will be dichotomized into two categories: clinically improved or unchanged/deteriorated. An analysis of covariance (ANCOVA) will be carried out for all secondary outcomes to determine differences between groups across time using demographical and clinical baseline variables as covariates. The level of significance will be set at $p<0.05$ for all statistical tests and corrected for multiple comparisons when necessary.

\section{Trial registration}

The trial has been registered at ClinicalTrials.gov and identified as NCT04507542.

\section{Discussion}

Chronic stroke patients with residual motor deficits experience limitations in activities of daily living and restrictions in participation in community life [35]. The impact of these residual motor deficits on function coupled with low levels of physical activity can lead to poor emotional well-being, life satisfaction and quality of life $[12,38]$. There is increasing interest in developing home and community-based interventions for chronic stroke patients to address their needs and improve their autonomy, participation and overall well-being [13, 34].

MST aims at improving motor and cognitive functions, emotional well-being and quality of life in stroke patients and could be a feasible intervention to apply in the chronic phase [32, 71, 79]. We have adapted the original MST program for home use and we have increased training intensity and variability, incorporated group sessions, and modified the protocol to boost learning by enhancing motivation and promoting more autonomy. The incorporation of these changes and the adaptation of the program take into account the Medical Research Council Framework for Developing and Evaluating Complex Interventions. In order to further develop MST we identified relevant evidence in the literature and developed a theoretical understanding of the processes of change [33]. Moreover, we have modelled the intervention process and outcomes, and assessed feasibility with a pilot study.

The study has been designed following the CONSORT guidelines for conducting clinical trials. The evaluation protocol includes baseline variables such as social support, perseverance or musical reward to take into account individual differences that may modulate the treatment effect. The outcomes of the study address various dimensions of functioning, with instruments that evaluate body functions, activity and participation. In addition, we have included measures of self-regulation and self-efficacy. Considering that the intervention is home and community-based, these factors may have a crucial role in treatment adherence and success.

We expect that patients treated with eMST will show larger functional improvements than patients treated with the control therapy regimen. On the basis that MST improves several dimensions of functionality beyond the motor function, we expect that patients will improve their mood and emotional well-being after MST.

\section{Abbreviations \\ Al: Artificial intelligence; ARAT: Action Research Arm Test; BRIEF: Behaviou Rating Inventory of Executive Function; eMST: Enriched Music-Supported Therapy; FMA: Fugl-Meyer Assessment of Motor Recovery after Stroke; GRASP: Graded Repetitive Arm Supplementary Program; MST: Music- Supported Therapy; MTCSI: Music Therapy Communication and Social Interaction scale}

\section{Acknowledgments}

This work was supported by the Ministerio de Ciencia, Innovación y Universidades (ref. PGC2018-099859-B-100) to A.R.F, by 2017-SGR-172 from Generalitat de Catalunya to J.L.A. Study resulting from the 201729.30 project, funded by La Marató de TV3. We thank CERCA Programme / Generalitat de Catalunya for institutional support.

\section{Trial sponsor}

Bellvitge Biomedical Research Institute

Avinguda de la Granvia de l'Hospitalet, 199, 08908

L'Hospitalet de Llobregat, Barcelona - Spain

\section{Authors' contributions}

A.R.F., and J.L.A. conceived the study and A.R.F., J.L.A., J.G.S., E.M., D.S.P., and E.D. designed the study. T.F.M., and T.S. contributed to the refinement of the study design. J.L.A., D.S.P., and J.C. designed the app to conduct the musical intervention. P.R., A.M.P., and A.T. designed the musical group sessions. All authors revised the article and approved the final manuscript. A.R.F. and J.L.A. are grant holders for this study.

\section{Funding}

Fundació La Marato TV3 (2016, Stroke and traumatic spinal cord and brain injury program) to A.R.F. and J.L.A.

\section{Availability of data and materials}

Data and materials can be accessed by contacting the corresponding author and in the research group webpage: https://www.brainvitge.org

\section{Ethics approval and consent to participate}

The study is approved by the ethics committee of Bellvitge University Hospital and Hospitals del Mar i l'Esperança (Barcelona, Spain) and participants will provide written consent to enrol in the study.

\section{Consent for publication}

In Fig. 3, the second author appears in the figure. We have her consent to use her image.

\section{Competing interests}

All authors declare no conflicts of interest.

\section{Author details}

${ }^{1}$ Cognition and Brain Plasticity Unit, Bellvitge Biomedical Research Institute, L'Hospitalet de Llobregat, 08907 Barcelona, Spain. ${ }^{2}$ Escola Universitària d'Infermeria i Teràpia Ocupacional de Terrassa, Autonomous University of 
Barcelona, C/ de la Riba, 90, 08221 Terrassa, Spain. ${ }^{3}$ Institute of Neurosciences, University of Barcelona 08035 Barcelona, Spain. ${ }^{4}$ Artificial Intelligence Research Institute, Spanish National Research Council, Bellaterra, 08193 Barcelona, Spain. ${ }^{5}$ Department of Physical Medicine and Rehabilitation, John Hopkins University, Baltimore, MD 21287, USA. ${ }^{6}$ Department of Neurology, University of Lübeck, 23562 Lübeck, Germany. ${ }^{7}$ Nordoff-Robbins Center for Music Therapy, New York University, New York 10012, USA. ${ }^{8}$ Rehabilitation Science Program, Steinhardt School of Culture, Education and Human Development, New York University, 10003 New York, USA. ${ }^{9}$ Department of Physical and Rehabilitation Medicine, Hospitals del Mar i I'Esperança, 08003 Barcelona, Spain. ${ }^{10}$ Cognitive Brain Research Unit, Department of Psychology and Logopedics, University of Helsinki, 00014 Helsinki, Finland. ${ }^{11}$ Department of Cognition, Development and Educational Psychology, University of Barcelona, 08035 Barcelona, Spain. ${ }^{12}$ Institució Catalana de Recerca i Estudis Avançats, 08010 Barcelona, Spain.

\section{Received: 21 August 2020 Accepted: 1 December 2020} Published online: 12 January 2021

\section{References}

1. Abe M, Schambra H, Wassermann EM, Luckenbaugh D, Schweighofer N, Cohen LG. Reward improves long-term retention of a motor memory through induction of offline memory gains. Curr Biol. 2011;21(7):557-62 https://doi.org/10.1016/j.cub.2011.02.030.

2. Albert SJ, Kesselring J. Neurorehabilitation of stroke. J Neurol. 2012;259(5): 817-32 https://doi.org/10.1007/s00415-011-6247-y.

3. Aluru V, Lu Y, Leung A, Verghese J, Raghavan P. Effect of auditory constraints on motor performance depends on stage of recovery poststroke. Front Neurol. 2014;5(JUN) https://doi.org/10.3389/fneur.2014.00106.

4. Amengual, J. L., Rojo, N., de las Heras, MV., Marco-Pallarés, J., Grau-Sánchez, J., Schneider, S., Vaquero, L., Juncadella, M., Montero, J., Mohammadi, B., Rubio, F., Rueda, N., Duarte, E., Grau, C., Altenmüller, E., Münte, T. F., Rodríguez-Fornells, A., Marco-Pallarés, J., Grau-Sánchez, J., ... RodríguezFornells, A. (2013). Sensorimotor plasticity after music-supported therapy in chronic stroke patients revealed by Transcranial magnetic stimulation. PLoS One, 8(4), e61883. https://doi.org/10.1371/journal.pone.0061883.

5. Andrade EM, Arce C, Seoane G. Adaptación al español del cuestionario "Perfil de los Estados de Ánimo" en una muestra de deportistas. Psicothema. 2002;14(4):708-13.

6. Aron A, Aron EN, Smollan D. Inclusion of Other in the Self Scale and the structure of interpersonal closeness. Journal of Personality andSocial Psychology. 1992;63(4):596-612. https://doi.org/10.1037/0022-3514.63.4.596.

7. Ashe MC, Miller WC, Eng JJ, Noreau L. Older adults, chronic disease and leisure-time physical activity. Gerontology. 2009;55(1):64-72 https://doi.org/ 10.1159/000141518.

8. Barreca S, Gowland C, Stratford P, Huijbregts M, Griffiths J, Torresin W, Dunkley M, Miller P, Masters L. Development of the Chedoke arm and hand activity inventory: theoretical constructs, item generation, and selection. Topics in Stroke Rehabilitation. 2004;11(4):31-42 https://doi.org/10.1310/ JU8P-UVK6-68WW-CF3W.

9. Barreca SR, Gowland CK, Stratford P, Huijbregts M, Griffiths J, Torresin W, Dunkley M, Miller P, Masters L. Development of the Chedoke arm and hand activity inventory: theoretical constructs, item generation, and selection. Top Stroke Rehabil. 2015;11(4):31-42 https://doi.org/10.1310/ JU8P-UVK6-68VW-CF3W.

10. Barriopedro MI, Quintana I, Ruiz LM. La perseverancia y pasión en la consecución de objetivos: Validación española de la Escala grit de Duckworth. [perseverance and passion in achieving the objectives: Spanish validation of the Duckworth's grit scale]. Rev Int Cienc Deporte. 2018;14(54): 297-308 https://doi.org/10.5232/ricyde2018.05401.

11. Basuelas Herreras E. BRIEF-A ( forma abreviada ): Análisis propiedades psicométricas en una muestra española BRIEF-A ( short ): analysis psychometric properties in a Spanish sample. Arch Neurocien. 2016;21(4):6-15.

12. Beck AT, Steer RA, Brown GK. Manual for the Beck depression inventory-II. San Antonio: Psychological Corporation; 1996.

13. Bell AP, Perry R, Peng M, Miller AJ. The Music Therapy Communication and Social Interaction Scale (MTCSI): Developing a new Nordoff-Robbins scale and examining interrater reliability. Music Ther Perspect. 2014;32(1):61-70.

14. Billinger SA, Arena R, Bernhardt J, Eng JJ, Franklin BA, Johnson CM, MackayLyons M, Macko RF, Mead GE, Roth EJ, Shaughnessy M, Tang A. Physical activity and exercise recommendations for stroke survivors: A statement for healthcare professionals from the American Heart Association/American Stroke Association. Stroke. 2014;45(8):2532-53 https://doi.org/10.1161/STR. 0000000000000022

15. Bunketorp-Käll L, Lundgren-Nilsson Å, Samuelsson H, Pekny T, Blomvé K, Pekna M, Pekny M, Blomstrand C, Nilsson M. Long-term improvements after multimodal rehabilitation in late phase after stroke. Stroke. 2017:48(7):191624 https://doi.org/10.1161/STROKEAHA.116.016433.

16. Calero MD, Arnedo ML, Navarro E, Ruiz-Pedrosa M, Carnero C. Usefulness of a 15-item version of the Boston naming test in neuropsychological assessment of low-educational elders with dementia. J Gerontol Se B Psychol Sci Soc Sci. 2002;57(2):P187-91 https://doi.org/10.1093/geronb/57.2.P187.

17. Chan DK, Lonsdale C, Ho PY, Yung PS, Chan KM. Patient motivation and adherence to Postsurgery rehabilitation exercise recommendations: the influence of physiotherapists' autonomy-supportive behaviors. Arch Phys Med Rehabil. 2009;90(12):1977-82 https://doi.org/10.1016/j.apmr.2009.05.024.

18. Chen HM, Chen CC, Hsueh IP, Huang SL, Hsieh CL. Test-retest reproducibility and smallest real difference of 5 hand function tests in patients with stroke. Neurorehabil Neural Repair. 2009;23(5):435-40 https:// doi.org/10.1177/1545968308331146.

19. Chen S-Y, Winstein CJ. A systematic review of voluntary arm recovery in Hemiparetic stroke. J Neurol Phys Ther. 2009;33(1):2-13 https://doi.org/10. 1097/NPT.0b013e318198a010.

20. Connell LA, McMahon NE, Harris JE, Watkins CL, Eng JJ. A formative evaluation of the implementation of an upper limb stroke rehabilitation intervention in clinical practice: a qualitative interview study. Implementation Sci. 2014;9:90 https://doi.org/10.1186/s13012-014-0090-3.

21. Cross I. Music, cognition, culture, and evolution. Ann N Y Acad Sci. 2001; 930(1):28-42 https://doi.org/10.1111/j.1749-6632.2001.tb05723.x.

22. Daly JJ, McCabe JP, Holcomb J, Monkiewicz M, Gansen J, Pundik S. Longdose intensive therapy is necessary for strong, clinically significant, upper limb functional gains and retained gains in severe/moderate chronic stroke. Neurorehabil Neural Repair. 2019;33(7):523-37 https://doi.org/10.1177/ 1545968319846120.

23. Deci EL, Ryan RM. The "what" and "why" of goal pursuits: human needs and the self-determination of behavior. Psychol Inq. 2000;11(4):227-68 https:// doi.org/10.1207/S15327965PLI1104_01.

24. Deterding S, O'Hara K, Sicart M, Dixon D, Nacke L. Gamification: using game design elements in non-gaming contexts. In: Conference on Human Factors in Computing Systems - Proceedings; 2011. p. 2425-8. https://doi.org/10. 1145/1979742.1979575.

25. Duckworth AL, Peterson C, Matthews MD, Kelly DR. Grit: perseverance and passion for long-term goals. J Pers Soc Psychol. 2007;92(6):1087-101 https:// doi.org/10.1037/0022-3514.92.6.1087.

26. Feigin $\mathrm{VL}$, Mensah GA, Norrving B, Murray $C J L$, Roth GA. Atlas of the global burden of stroke (1990-2013): the GBD 2013 study. Neuroepidemiology. 2015;45(3):230-6 https://doi.org/10.1159/000441106.

27. Freeman WJ. A neurobiological role of music in social bonding. In: Wallin N, Merker B, Brown S, editors. The origins of music. Cambridge: MIT Press; 2000. p. 411-24.

28. Friedman N, Reinkensmeyer D, Bachman M. A real-time interactive MIDI glove for domicile stroke rehabilitation. In: Lecture Notes in Computer Science (Including Subseries Lecture Notes in Artificial Intelligence and Lecture Notes in Bioinformatics), 6764 LNCS(PART 4); 2011. p. 151-8. https:// doi.org/10.1007/978-3-642-21619-0_20.

29. Fugl-Meyer AR, Jääskö L, Leyman I, Olsson S, Steglind S. The post-stroke hemiplegic patient. A method for evaluation of physical performance. Scand J Rehabil Med. 1975;7(1):13-31.

30. Fujioka T, Dawson DR, Wright R, Honjo K, Chen JL, Chen JJ, Black SE, Stuss DT, Ross B. The effects of music-supported therapy on motor, cognitive, and psychosocial functions in chronic stroke. Ann N Y Acad Sci. 2018;1423(1): 264-74 https://doi.org/10.1111/nyas.13706.

31. García-Rudolph A, Laxe S, Saurí J, Opisso E, Tormos JM, Bernabeu M. Evidence of chronic stroke rehabilitation interventions in activities and participation outcomes: systematic review of meta-analyses of randomized controlled trials. Eur J Phys Rehabil Med. 2019;55(6):695-709 https://doi.org/ 10.23736/S1973-9087.19.05814-3.

32. GBD 2016 DALYs and HALE Collaborators. Global, regional, and national disability-adjusted life-years (DALYs) for 333 diseases and injuries and healthy life expectancy (HALE) for 195 countries and territories, 19902016: a systematic analysis for the global burden of disease study 2016. 
Lancet. 2017;390(10100):1260-344 https://doi.org/10.1016/S01406736(17)32130-X.

33. Gebruers N, Vanroy C, Truijen S, Engelborghs S, De Deyn PP. Monitoring of physical activity after stroke: A systematic review of Accelerometry-based measures. Arch Phys Med Rehabil. 2010;91(2):288-97 https://doi.org/10. 1016/j.apmr.2009.10.025.

34. Grau-Sánchez J, Duarte E, Ramos-Escobar N, Sierpowska J, Rueda N, Redón S, Veciana de las Heras, M., Pedro, J., Särkämö, T., \& Rodríguez-Fornells, A. Music-supported therapy in the rehabilitation of subacute stroke patients: a randomized controlled trial. Ann N Y Acad Sci. 2018;1423(1):318-28 https:// doi.org/10.1111/nyas.13590.

35. Grau-Sánchez J, Münte TF, Altenmüller E, Duarte E, Rodríguez-Fornells A. Potential benefits of music playing in stroke upper limb motor rehabilitation. Neurosci Biobehav Rev. 2020;112(October 2019):585-99 https://doi.org/10.1016/..neubiorev.2020.02.027

36. Graven, C., Brock, K., Hill, K., \& Joubert, L. (2011). Are rehabilitation and/or care co-ordination interventions delivered in the community effective in reducing depression, facilitating participation and improving quality of life after stroke? Disabil Rehabil (33, 17-18, pp. 1501-1520). https://doi.org/10. 3109/09638288.2010.542874.

37. Hankey GJ, Jamrozik K, Broadhurst RJ, Forbes S, Anderson CS. Long-term disability after first-ever stroke and related prognostic factors in the Perth community stroke study, 1989-1990. Stroke. 2002;33(4):1034-40 https://doi. org/10.1161/01.str.0000012515.66889.24.

38. Harris JE, Eng JJ, Miller WC, Dawson AS. A self-administered graded repetitive arm supplementary program (GRASP) improves arm function during inpatient stroke rehabilitation: A multi-site randomized controlled trial. Stroke. 2009;40(6):2123-8 https://doi.org/10.1161/STROKEAHA.108. 544585.

39. Hartman-Maeir A, Soroker N, Ring H, Avni N, Katz N. Activities, participation and satisfaction one-year post stroke. Disabil Rehabil. 2007;29(7):559-66 https://doi.org/10.1080/09638280600924996.

40. Hildebrand M, Brewer M, Wolf T. The impact of mild stroke on participation in physical fitness activities. Stroke Res Treat. 2012;2012:548682 https://doi. org/10.1155/2012/548682.

41. Jones TA. Motor compensation and its effects on neural reorganization after stroke. Nat Rev Neurosci. 2017;18(5):267-80 https://doi.org/10.1038/nrn.2017.26.

42. Kitago T, Krakauer JW. Motor learning principles for neurorehabilitation. In: Barnes MP, Good DC, editors. Handbook of Clinical Neurology, vol. 110. 1st ed: Elsevier B.V; 2013. p. 93-103. https://doi.org/10.1016/B978-0-444-52901-5. 00008-3.

43. Krakauer JW. Motor learning: its relevance to stroke recovery and neurorehabilitation. Curr Opin Neurol. 2006;19(1):84-90 https://doi.org/10. 1097/01.wco.0000200544.29915.cc.

44. Lackland DT, Roccella EJ, Deutsch AF, Fornage M, George MG, Howard G, Kissela BM, Kittner SJ, Lichtman JH, Lisabeth LD, Schwamm LH, Smith $\mathrm{EE}$, Towfighi A. Factors influencing the decline in stroke mortality: A statement from the American Heart Association/American Stroke Association. Stroke. 2014;45(1):315-53 https://doi.org/10.1161/01.str. 0000437068.30550.cf.

45. Landeta O, Calvete E. Adaptación y validación de la escala multidimensional de apoyo social percibido. Ansiedad Estrés. 2002:173-82 https://dialnet. unirioja.es/servlet/articulo?codigo $=306806$.

46. Lev EL, Owen SV. A Measure of Self-Care Self-Efficacy. Res Nursing Healt. 1996;19:421-29

47. Levy BB, Luong D, Perrier L, Bayley MT, Munce SEP. Peer support interventions for individuals with acquired brain injury, cerebral palsy, and spina bifida: A systematic review. BMC Health Serv Res. 2019;19(1):288 https://doi.org/10.1186/s12913-019-4110-5.

48. Lozano Gallego M, Hernández Ferrándiz M, Turró Garriga O, Pericot Nierga I, López-Pousa S, Vilalta Franch J. Validación del Montreal Cognitive Assessment ( MoCA ): test de cribado para el deterioro cognitivo leve. Datos preliminares. Alzheimer Real Invest Demenc. 2009;43:4-11 https://silo. tips/download/validacion-del-montreal-cognitive-assessment-moca-test-decribado-para-el-deteri.

49. Lyle RC. A performance test for assessment of upper limb function in physical rehabilitation treatment and research. Int J Rehabil Res. 1981;4(4): 483-92.

50. Mack WJ, Freed DM, Williams BW, Henderson WW. Boston naming test: shortened versions for use in Alzheimer's disease. J Gerontol. 1992;47(3): P154-8 https://doi.org/10.1093/GERONJ/47.3.P154.
51. Malone TW. Toward a theory of intrinsically motivating instruction. Cogn Sci. 1981;5(4):333-69 https://doi.org/10.1016/S0364-0213(81)80017-1.

52. Marin RS, Biedrzycki RC, Firinciogullari S, Rao K, Price TR, Stadlan E. Reliability and validity of the apathy evaluation scale. Psychiatry Res. 1991;38(2):143-62 https://doi.org/10.1016/0165-1781(91)90040-V.

53. Marqués NO, Caro IA, Uterga Valiente JM, Rodríguez SM. Normative data for a Spanish version of the Rey auditory-verbal learning test in older people. Span J Psychol. 2013;16:E60 https://doi.org/10.1017/sjp.2013.63.

54. Mas-Herrero E, Marco-Pallares J, Lorenzo-Seva U, Zatorre RJ, RodriguezFornells A. Individual differences in music reward experiences. Music Percept Interdiscip J. 2013;31(2):118-38 https://doi.org/10.1525/mp.2013.31. 2.118.

55. Mas-Herrero E, Zatorre RJ, Rodriguez-Fornells A, Marco-Pallarés J. Dissociation between musical and monetary reward responses in specific musical Anhedonia. Curr Biol. 2014;24:1-6 https://doi.org/10.1016/j.cub.2014. 01.068 .

56. Mathiowetz V, Volland G, Kashman N, Weber K. Adult norms for the box and block test of manual dexterity. Am J Occup Ther. 1985;39(6):386-91.

57. Mathiowetz V, Weber K, Volland G, Kashman N, Cummings R. Reliability and validity of grip and pinch strength evaluations. J Hand Surg. 1984;9(2):222-6 https://doi.org/10.1016/S0363-5023(84)80146-X.

58. Mayo NE, Wood-Dauphinee S, Carlton R, Durcan L, Carlton J. Activity, participation, and quality of life 6 months poststroke. Arch Phys Med Rehabil. 2002;83(8):1035-42 https://doi.org/10.1053/apmr.2002.33984.

59. McKevitt C, Fudge N, Redfern J, Sheldenkar A, Crichton S, Rudd AR, Forster A, Young J, Nazareth I, Silver LE, Rothwell PM, Wolfe CDA. Self-reported long-term needs after stroke. Stroke. 2011;42(5):1398-403 https://doi.org/10. 1161/STROKEAHA.110.598839.

60. McNair D, Lorr M, Droppleman L. Manual for the profile of mood states. San Diego: Educational and Industrial Testing Services; 1971.

61. Meyer S, Verheyden G, Brinkmann N, Dejaeger E, De Weerdt W, Feys $H_{\text {, }}$ Gantenbein AR, Jenni W, Laenen A, Lincoln N, Putman K, Schuback B, Schupp W, Thijs V, De Wit L. Functional and motor outcome 5 years after stroke is equivalent to outcome at 2 months: follow-up of the collaborative evaluation of rehabilitation in stroke across Europe. Stroke. 2015;46(6):1613$9 \mathrm{https}: / /$ doi.org/10.1161/STROKEAHA.115.009421.

62. Mithen $\mathrm{S}$. The music instinct: the evolutionary basis of musicality. Ann N Y Acad Sci. 2009;1169:3-12 https://doi.org/10.1111/j.1749-6632.2009.04590.x.

63. Mithen S, Morley I, Wray A, Tallerman M, Gamble C. The singing Neanderthals: the origins of music, language, mind and body. Camb Archaeol J. 2006;16(1):97-112 https://doi.org/10.1017/S0959774306000060.

64. Mulder M, Nijland R. Stroke Impact Scale. J Physiother. 2016;62(2):117 https://doi.org/10.1016/j.jphys.2016.02.002.

65. Nasreddine ZS, Phillips NA, BÃ@dirian, V., Charbonneau, S., Whitehead, V., Collin, I., Cummings, J. L., \& Chertkow, H. The Montreal cognitive assessment, MoCA: A Brief screening tool for mild cognitive impairment. J Am Geriatr Soc. 2005;53(4):695-9 https://doi.org/10.1111/j.1532-5415.2005. 53221.x.

66. O'Doherty JP. Reward representations and reward-related learning in the human brain: insights from neuroimaging. Curr Opin Neurobiol. 2004;14(6): 769-76 https://doi.org/10.1016/j.conb.2004.10.016.

67. Page SJ, Fulk GD, Boyne P. Clinically important differences for the upperextremity Fugl-Meyer scale in people with minimal to moderate impairment due to chronic stroke. Phys Ther. 2012;92(6):791-8 https://doi.org/10.2522/ ptj.20110009.

68. Park YJ, Lee CY. Effects of community-based rehabilitation program on activities of daily living and cognition in elderly chronic stroke survivors. J Phys Ther Sci. 2016;28(11):3264-6 https://doi.org/10.1589/jpts.28.3264.

69. Parker VM, Wade DT, Langton Hewer R. Loss of arm function after stroke: measurement, frequency, and recovery. Int Rehabil Med. 1986; 8(2):69-73.

70. Peña-Casanova J, Quiñones-Úbeda S, Gramunt-Fombuena N, Aguilar M, Casas L, Molinuevo JL, Robles A, Rodríguez D, Barquero MS, Antúnez C, Martínez-Parra C, Frank-García A, Fernández M, Molano A, Alfonso V, Sol JM, Blesa R. Spanish multicenter normative studies (NEURONORMA project): norms for Boston naming test and token test. Arch Clin Neuropsychol. 2009; 24(4):343-54 https://doi.org/10.1093/arclin/acp039.

71. Peretz I, Champod AS, Hyde K. Varieties of musical disorders. The Montreal Battery of Evaluation of Amusia. Ann New York Acad Sci. 2003;999:58-75.

72. Platz T, Pinkowski $C$, van Wijck F, Kim IH, di Bella P, Johnson G. Reliability and validity of arm function assessment with standardized guidelines for 
the Fugl-Meyer test, action research arm test and box and block test: A multicentre study. Clin Rehabil. 2005;19(4):404-11 https://doi.org/10.1191/ 0269215505 cr8320a.

73. Raghavan P, Geller D, Guerrero N, Aluru V, Eimicke JP, Teresi JA, Ogedegbe G, Palumbo A, Turry A. Music upper limb therapy_-integrated: an enriched collaborative approach for stroke rehabilitation. Front Hum Neurosci. 2016; 10:498 https://doi.org/10.3389/fnhum.2016.00498.

74. Rey A. L' examen Clinique en Psychologie (2e éd.). Presses universitaires de France; 1964.

75. Ripollés P, Rojo N, Grau-Sánchez J, Amengual JLL, Càmara E, Marco-Pallarés J, Juncadella M, Vaquero L, Rubio F, Duarte E, Garrido C, Altenmüller E, Münte TF, Rodríguez-Fornells A. Music supported therapy promotes motor plasticity in individuals with chronic stroke. Brain Imaging Behav. 2016;10(4): 1289-307 https://doi.org/10.1007/s11682-015-9498-x.

76. Robertson IH, Manly T, Andrade J, Baddeley BT, Yiend J. "Oops!": performance correlates of everyday attentional failures in traumatic brain injured and normal subjects. Neuropsychologia. 1997;35(6):747-58 https:// doi.org/10.1016/S0028-3932(97)00015-8.

77. Rodriguez-Fornells A, Rojo N, Amengual JL, Ripollés P, Altenmüller E, Münte TF. The involvement of audio-motor coupling in the music-supported therapy applied to stroke patients. Ann N Y Acad Sci. 2012;1252(1):282-93 https://doi.org/10.1111/j.1749-6632.2011.06425.x.

78. Roth RM, Isquith PK, Gioia GA. Behavior rating inventory of executive function-adult version: professional manual. Lutz: Psychological Assessment Resources, Inc; 2005

79. Ryan RM. Control and information in the intrapersonal sphere: An extension of cognitive evaluation theory. J Person Soc Psychol. 1982;43:450-61.

80. Ryan RM, Connell JP. Perceived locus of causality and internalization: Examining reasons for acting in two domains. J Person Soc Psychol. 1989; 57:749-61.

81. Sanchez-Pinsach D, Mülâyim MO, Grau-Sánchez J, Segura E, Juan-Corbella B, Arcos JL, Cerquides J, Messaggi-Sartor M, Duarte E, Rogriguez-Fornells A. Design of an Al platform to support home-based self-training music interventions for chronic stroke patients. In: Sabater-Mir J, Torra V, Aguiló I, González-Hidalgo M, editors. Frontiers in Artificial Intelligence and Applications, vol. 319: IOS Press; 2019. p. 170-5. https://doi.org/10.3233/ FAIA190120.

82. Sanz J, Perdigón AL, Vázquez C. Adaptación española del Inventario para la Depresión de Beck-II (BDI-II): 2 . Propiedades psicométricas en población general. Clin Salud. 2003;14(3):249-80.

83. Schneider $S$, Schönle P, Altenmüller E, Münte T. Using musical instruments to improve motor skill recovery following a stroke. J Neurol. 2007;254(10): 1339-46 https://doi.org/10.1007/s00415-006-0523-2.

84. Schönberger M, Hansen NR, Pedersen DT, Zeeman P, Jørgensen JR. The relationship between physical fitness and work integration following stroke. Brain Impairment. 2010;11(3):262-9 https://doi.org/10.1375/brim.11.3.262

85. Street AJ, Magee WL, Bateman A, Parker M, Odell-Miller H, Fachner J. Homebased neurologic music therapy for arm hemiparesis following stroke: results from a pilot, feasibility randomized controlled trial. Clin Rehabil. 2018; 32(1):18-28 https://doi.org/10.1177/0269215517717060.

86. Street AJ, Magee WL, Odell-Miller H, Bateman A, Fachner JC. Home-based neurologic music therapy for upper limb rehabilitation with stroke patients at community rehabilitation stage - a feasibility study protocol. Front Hum Neurosci. 2015;9:480 https://doi.org/10.3389/fnhum.2015.00480.

87. Sullivan JE, Crowner BE, Kluding PM, Nichols D, Rose DK, Yoshida R, Pinto Zipp G. Outcome measures for individuals with stroke: process and recommendations from the American Physical Therapy Association neurology section task force. Phys Ther. 2013;93(10):1383-96 https://doi.org/ 10.2522/ptj.20120492.

88. Tarr, B., Launay, J., \& Dunbar, R. I. M. (2014). Music and social bonding: "selfother" merging and neurohormonal mechanisms. Frontiers in Psychology, 5(SEP). https://doi.org/10.3389/fpsyg.2014.01096.

89. Thurstone LL. Primary mental abilities. Chicago University Press; 1938.

90. United Nations. Convention on the rights of persons with disabilities. In: Treaty Series, vol. 2515; 2006. http://www.un.org/disabilities/documents/ convention/convoptprot-e.pdf.

91. van der Lee JH, Beckerman H, Lankhorst GJ, Bouter LM. The responsiveness of the action research arm test and the Fugl-Meyer assessment scale in chronic stroke patients. J Rehabil Med. 2001;33(3):110-3.

92. van der Lee JH, de Groot V, Beckerman H, Wagenaar RC, Lankhorst GJ, Bouter LM. The intra- and interrater reliability of the action research arm test: A practical test of upper extremity function in patients with stroke. Arch Phys Med Rehabil. 2001;82(1):14-9 https://doi.org/10.1053/apmr.2001. 18668.

93. Verheyden G, Nieuwboer A, De Wit L, Thijs V, Dobbelaere J, Devos H, Severijns D, Vanbeveren S, De Weerdt W. Time course of trunk, arm, leg, and functional recovery after ischemic stroke. Neurorehabil Neural Repair. 2008;22(2):173-9 https://doi.org/10.1177/1545968307305456.

94. Villeneuve M, Lamontagne A. Playing piano can improve upper extremity function after stroke: case studies. Stroke Res Treat. 2013;2013:159105 https://doi.org/10.1155/2013/159105.

95. Vuilleumier $P$, Trost W. Music and emotions: from enchantment to entrainment. Ann N Y Acad Sci. 2015;1337(1):212-22 https://doi.org/10. 1111/nyas. 12676.

96. Wade DT, Hewer RL. Functional abilities after stroke: measurement, natural history and prognosis. J Neurol Neurosurg Psychiatry. 1987;50(2):177-82 https://doi.org/10.1136/jnnp.50.2.177.

97. Wechsler D. WAIS-IV Administration and Scoring Manual. San Antonio: Psychological Corporation; 2008.

98. Wechsler D. WMS-IV. Escala de memoria de Wechsler-IV Manual técnico y de interpretación.Madrid: NCS Pearson, Inc; 2013.

99. White JH, Alston MK, Marquez JL, Sweetapple AL, Pollack MR, Attia J, Levi CR, Sturm J, Whyte S. Community-dwelling stroke survivors: function is not the whole story with quality of life. Arch Phys Med Rehabil. 2007;88(9):11406 https://doi.org/10.1016/j.apmr.2007.06.003.

100. Winstein CJ, Stein J, Arena R, Bates B, Cherney LR, Cramer SC, Deruyter F, Eng JJ, Fisher B, Harvey RL, Lang CE, MacKay-Lyons M, Ottenbacher KJ, Pugh S, Reeves MJ, Richards LG, Stiers W, Zorowitz RD. Guidelines for adult stroke rehabilitation and recovery: A guideline for healthcare professionals from the American Heart Association/American Stroke Association. Stroke. 2016; 47(6):e98-e169 https://doi.org/10.1161/STR.0000000000000098.

101. Wulf G, Lewthwaite R. Optimizing performance through intrinsic motivation and attention for learning: the OPTIMAL theory of motor learning. Psychon Bull Rev. 2016;23(5):1382-414 https://doi.org/10.3758/s13423-015-0999-9.

102 Zatorre RJ, Salimpoor VN. From perception to pleasure: music and its neural substrates. Proc Natl Acad Sci. 2013;110(Supplement_2):10430-7 https://doi. org/10.1073/pnas.1301228110.

103. Zimet GD, Dahlem NW, Zimet SG, Farley GK. The multidimensional scale of perceived social support. J Pers Assess. 1988;52(1):30-41 https://doi.org/10. 1207/s15327752jpa5201_2.

\section{Publisher's Note}

Springer Nature remains neutral with regard to jurisdictional claims in published maps and institutional affiliations.

Ready to submit your research? Choose BMC and benefit from:

- fast, convenient online submission

- thorough peer review by experienced researchers in your field

- rapid publication on acceptance

- support for research data, including large and complex data types

- gold Open Access which fosters wider collaboration and increased citations

- maximum visibility for your research: over $100 \mathrm{M}$ website views per year

At BMC, research is always in progress.

Learn more biomedcentral.com/submissions 